\title{
Study of rigidity of semiconducting vanadate glasses and its importance in use of coatings
}

\author{
YASSER B SADDEEK ${ }^{1, *}$ and M S GAAFAR ${ }^{2}$ \\ Physics Department, Faculty of Science, Majmaa University, Zulfi, Saudi Arabia \\ ${ }^{1}$ Physics Department, Faculty of Science, Al-Azhar University, P. O. Box 71452, Assiut, Egypt \\ ${ }^{2}$ Ultrasonic Laboratory, National Institute for Standards, Tersa Str., P. O. Box 136, El-Haram, El-Giza 12211, Egypt
}

MS received 21 January 2013; revised 22 March 2013

\begin{abstract}
The elastic moduli of some multicomponent vanadate based glasses were analysed in terms of the bond compression model by some physical parameters such as, the density, average stretching force constant and average atomic ring size. These parameters were calculated for all the glass series and for all the glass composition to estimate the rigidity of these glasses. The results showed that the average force constant and the elastic moduli of these glasses are sensitive to the decrease in $\mathrm{PbO}$ content. This behaviour was attributed to the increase in the molar volume and the role of different modifiers. These parameters along with the coordination number of the glasses affect the glass transition temperature. The correlation between the elastic moduli and thermal properties of these samples showed that $0.25 \mathrm{MoO}_{3}-0.25 \mathrm{PbO}-0.5 \mathrm{~V}_{2} \mathrm{O}_{5}$ glass is the most rigid and has an applicable glass transition temperature for coating.
\end{abstract}

Keywords. Vanadate glasses; molar volume; elastic properties.

\section{Introduction}

Understanding of the physical properties of semiconducting glasses has increased considerably following recognition of their potential applications for optical and memory switching devices and electrochemical batteries (Wells 1975; Ghosh 1988; Livage et al 1990; Montani et al 1992; Rao 2002). Semiconducting glasses can be fabricated from transition metal oxides (e.g. $\mathrm{V}_{2} \mathrm{O}_{5}, \mathrm{PbO}$, $\mathrm{MoO}_{3} \ldots$ ) which constitute a class of non-conventional network formers (Baiocchi et al 1982; Josso and Calvarin 1986; Sidkey et al 2002). Due to the unique structural chemistry of crystalline oxides such as $\mathrm{PbO}$ and $\mathrm{V}_{2} \mathrm{O}_{5}$ (Calestani et al 1985), their counterpart lead vanadate glasses have wide glass-forming region. These glasses have been studied using electron spin resonance (ESR), magnetic susceptibility, thermodynamic measurements and DTA (Baiocchi et al 1982; Momo et al 1982; Calestani et al 1985; Josso and Calvarin 1986; Agostinelli et al 1986; Mandal and Ghosh 1993). Also, lead- and molybdenum-containing glasses were reported to be potential candidates for practical applications as amorphous semiconductors, for waste storage, infrared transmission components, thermal and mechanical sensors, reflecting windows or as catalysts for petroleum hydrotreatment (Dimitriev et al 1981, 1983a,b; Dimitriev and Mihailova

*Author for correspondence (ysaddeek@gmail.com)
1990; Dimitrov and Dimitrov 1990; Dumbaugh and Lapp 1992; Iordanova et al 1994; Dimitrov 1995; Hayakawa et al 1995; Qiu et al 1997; Bahgat et al 1999; El Mallawany 2002; Mouhsine et al 2003; Hand et al 2005; Ramesh and Sastry 2006; Pisarska et al 2008). The semiconducting properties of these glasses arises from the transfer of charge carriers (electronic or polaronic) from lowervalence states $\left(\mathrm{V}^{4+}\right)$ to higher-valence states $\left(\mathrm{V}^{5+}\right)$ of the vanadium ions. IR spectral studies on a large number of these glasses revealed the existence of two different forms of distribution of metal ions in relation to vanadiumoxygen polyhedra, where $\mathrm{Pb}^{2+}$ occupies an interstitial position (Mandal and Ghosh 1990).

Studies of the elastic moduli of the vanadate glasses give considerable information about their structure, since the elastic moduli are directly related to the interatomic forces and potentials, i.e. they are determined by the rigidity of the structure (Pauling 1940; Bridge et al 1983; Bridge and Higazy 1986; Paul et al 1999; Saddeek et al 2009a, b). In literature, there are few studies on ternary and quaternary vanadate glass systems such as $\mathrm{V}_{2} \mathrm{O}_{5}$ $\mathrm{BaO}-\mathrm{ZnO}$ or $\mathrm{La}_{2} \mathrm{O}_{3}$ and $\mathrm{Fe}_{2} \mathrm{O}_{3}$ are added to $\mathrm{PbO}-\mathrm{V}_{2} \mathrm{O}_{5}$ glass system (Kawamoto et al 1979, 1980; Music et al 1994).

The purpose of this study is to analyse quantitatively the elastic moduli and hence the rigidity of series of multicomponent vanadate based glasses (Bridge and Higazy 1986; Paul et al 1999; Saddeek et al 2009) in terms of the bond compression model (Bridge et al 1983; Bridge and 
Higazy 1986). The used parameters are the bulk modulus, cross-link density, the stretching force constant and the average atomic ring size of these glasses. A correlation of such elastic moduli to the thermal properties of these glasses (Paul et al 1999; Saddeek et al 2009) will be achieved to select the most applicable glass for coating.

\section{Theoretical analysis}

The structure of oxide glasses can be described in terms of the bond compression model which was first introduced by Bridge et al (1983) for the study of single-component glass, was later developed for multicomponent glasses (Bridge et al 1986). The model is based on the observation that the measured bulk modulus $K_{\mathrm{e}}$ of oxide glasses is always markedly smaller than $K_{\mathrm{bc}}$, the bulk modulus calculated under the assumption that each covalent bond experiences the linear contraction of the whole sample. Obviously, a sizable part of the volume change is due to a distortion of the network. In order to quantify the treatment of this effect, the model makes several assumptions:

(i) The elastic moduli only depend on both the 'connectivity' of the network (number of bonds per cation) and the average force constant $f$. The calculated bulk modulus $\left(K_{\mathrm{bc}}\right)$ according to this model can be estimated according to the relations:

$$
\begin{aligned}
& K_{\mathrm{bc}}=\left(\frac{\sum_{i} x n_{\mathrm{b}} r_{\mathrm{a}}^{2} f}{9}\right)(\mathrm{Gpa}), \\
& f=5 \cdot 28 N\left[\frac{X_{\mathrm{a}} X_{\mathrm{b}}}{r^{2}}\right]^{3 / 4}+30\left(\mathrm{Nm}^{-1}\right),
\end{aligned}
$$

where $x$ is the mole fraction of the component oxide, $n_{\mathrm{b}}$ is the number of network bonds per unit volume, $r_{\mathrm{a}}$ is the bond length, $N$ is the bond order (1, 2 or 3), $X_{\mathrm{a}}$ and $X_{\mathrm{b}}$ are the electronegativities of the anion and cation respectively. Accordingly, the average bond stretching-force constant $F$ for a three-dimensional polycomponent oxide glasses can be estimated (Bridge et al 1983).

(ii) The ratio between the calculated elastic moduli and the experimental one $\left(K_{\mathrm{bc}} / K_{\mathrm{e}}\right)$ is assumed to be directly proportional to the atomic ring size $(\ell)$. The atomic ring size is defined as the ring perimeter (number of bond times $\times$ bond length divided by $\pi$ ) and is given by the relation:

$$
\ell=\left[0.0106 \frac{f}{K_{\mathrm{e}}}\right]^{0.26}(\mathrm{~nm})
$$

Therefore, a value of $K_{\mathrm{bc}} / K_{\mathrm{e}} \gg 1$ indicates a relatively open (i.e. large ringed) three-dimensional network with ring size tending to increase with $K_{\mathrm{bc}} / K_{\mathrm{e}}$ and network bond bending (non-network compression) processes predominate when the glasses are subjected to bulk compression. The authors (Bridge et al 1983) found that the values of $K_{\mathrm{bc}} / K_{\mathrm{e}}$ are 3.05, 3.08, 4.39 and 6.62 for pure $\mathrm{SiO}_{2}, \mathrm{P}_{2} \mathrm{O}_{5}$, and $\mathrm{GeO}_{2}$ and $\mathrm{As}_{2} \mathrm{O}_{3}$ glasses, respectively. The conformable atomic ring size of these glasses are $0.58,0.567,0.631$ and $0.722 \mathrm{~nm}$, respectively (Bridge et al 1983).

\section{Results and discussion}

The quantitative analysis of the literature data (Paul et al 1999; Saddeek et al 2009a, b) in terms of the bond compression model was done using the set of parameters listed in table 1 . The set was adapted to the crystal structure of each oxide of the studied glass series (Wells 1975). These parameters are used in calculating the average stretching force constant $f$, the number of network bonds per unit volume $n_{\mathrm{b}}$, the bulk modulus $K_{\mathrm{bc}}$, the average atomic ring size $\ell$; and the ratio $K_{\mathrm{bc}} / K_{\mathrm{e}}$. In table 1 , one has two entries for the coordination number of $\mathrm{V}_{2} \mathrm{O}_{5}$ depending on the atomic composition, viz. $N=5$ and 6 , respectively (Music et al 1994; Saddeek et al 2009a, b).

The determination of the average cross-link density was based on the computation of both the coordination number of the constituent oxides. Also, it was found that the average force constant $(f)$ is governed by the reciprocal of the bond length. Previously (Bridge et al 1983) it has been argued that the high value of the ratio $K_{\mathrm{bc}} / K_{\mathrm{e}}>3$ indicates that network bond bending (or non-network bond compression) processes predominate when these materials are subjected to bulk compression. Thus, analysis of the computed elastic moduli according to the bondcompression model may be achieved for these glass series (Paul et al 1999; Saddeek et al 2009a, b) as follows.

\subsection{Analysis of elastic moduli}

3.1a $\mathrm{V}_{2} \mathrm{O}_{5}-\mathrm{PbO}$ series: Increasing $\mathrm{PbO}$ content on the expense of $\mathrm{V}_{2} \mathrm{O}_{5}$ in binary lead vanadate glasses results in

Table 1. Coordination number $(N)$, cation-anion bond length $\left(r_{\mathrm{a}}\right)$, first-order stretching force constant $(f)$ and electronegativity of cation $\left(X_{\mathrm{a}}\right)$, of oxides included in this study.

\begin{tabular}{lcccc}
\hline Oxides & $N$ & $r_{\mathrm{a}}(\mathrm{nm})$ & $f\left(\mathrm{Nm}^{-1}\right)$ & $X_{\mathrm{a}}$ \\
\hline $\mathrm{PbO}$ & 4 & $0 \cdot 244$ & $117 \cdot 03$ & $2 \cdot 33$ \\
$\mathrm{~V}_{2} \mathrm{O}_{5}$ & 5,6 & $0 \cdot 203$ & $203 \cdot 22$ & $1 \cdot 63$ \\
$\mathrm{Li}_{2} \mathrm{O}$ & 6 & $0 \cdot 210$ & $183 \cdot 57$ & 0.98 \\
$\mathrm{MoO}_{3}$ & 6 & $0 \cdot 202$ & $206 \cdot 25$ & $2 \cdot 16$ \\
\hline
\end{tabular}

Values of coordination number, bond length and electronegativity of cation were taken from Wells (1975) and Saddeek (2009). 
Table 2. Molar volume $\left(V_{\mathrm{m}}\right)$, number of network bonds per unit volume $\left(n_{\mathrm{b}}\right)$, average cross-link density $\left(\bar{n}_{\mathrm{c}}\right)$, bond compression bulk modulus $\left(K_{\mathrm{bc}}\right)$, ratio $\left(K_{\mathrm{bc}} / K_{\mathrm{e}}\right)$, Poisson's ratio $(\sigma)$, average force constant $(F)$, average ring diameter $(\ell)$, average coordination number $(N)$ and glass transition temperature $\left(T_{\mathrm{g}}\right)$ of studied glasses.

\begin{tabular}{|c|c|c|c|c|c|c|c|c|c|c|c|c|c|c|}
\hline \multicolumn{4}{|c|}{ Composition in mol fraction } & \multirow[b]{2}{*}{$\begin{array}{l}V_{\mathrm{m}} \times 10^{-6} \\
\left(\mathrm{~m}^{3} / \mathrm{mol}\right)\end{array}$} & \multirow[b]{2}{*}{$\begin{array}{c}n_{\mathrm{b}} \times 10^{28} \\
\left(\mathrm{~m}^{-3}\right)\end{array}$} & \multirow[b]{2}{*}{$\bar{n}_{\mathrm{c}}$} & \multirow[b]{2}{*}{$\begin{array}{c}K_{\mathrm{e}} \\
(\mathrm{GPa})\end{array}$} & \multirow[b]{2}{*}{$\begin{array}{c}K_{\mathrm{bc}} \\
(\mathrm{GPa})\end{array}$} & \multirow[b]{2}{*}{$\sigma$} & \multirow[b]{2}{*}{$K_{\mathrm{bc}} / K_{\mathrm{e}}$} & \multirow[b]{2}{*}{$\begin{array}{c}F \\
\left(\mathrm{Nm}^{-1}\right)\end{array}$} & \multirow[b]{2}{*}{$\begin{array}{c}\ell \\
(\mathrm{nm})\end{array}$} & \multirow[b]{2}{*}{$N$} & \multirow[b]{2}{*}{$\begin{array}{c}T_{\mathrm{g}} \\
(\mathrm{K})\end{array}$} \\
\hline $\mathrm{PbO}$ & $\mathrm{V}_{2} \mathrm{O}_{5}$ & $\mathrm{Li}_{2} \mathrm{O}$ & $\mathrm{MoO}_{3}$ & & & & & & & & & & & \\
\hline $0 \cdot 500$ & $0 \cdot 500$ & - & - & $39 \cdot 87$ & $6 \cdot 80$ & $2 \cdot 667$ & $39 \cdot 90$ & $58 \cdot 52$ & $0 \cdot 219$ & $1 \cdot 467$ & 165 & $4 \cdot 428$ & $4 \cdot 50$ & 521 \\
\hline $0 \cdot 488$ & $0 \cdot 512$ & - & - & $39 \cdot 80$ & $6 \cdot 83$ & $2 \cdot 677$ & $34 \cdot 89$ & $58 \cdot 91$ & $0 \cdot 219$ & $1 \cdot 689$ & 166 & $4 \cdot 593$ & $4 \cdot 51$ & 520 \\
\hline $0 \cdot 482$ & $0 \cdot 518$ & - & - & $40 \cdot 11$ & $6 \cdot 78$ & $2 \cdot 682$ & $36 \cdot 61$ & $58 \cdot 59$ & $0 \cdot 219$ & 1.600 & 166 & $4 \cdot 540$ & $4 \cdot 52$ & 518 \\
\hline $0 \cdot 452$ & $0 \cdot 548$ & - & - & $41 \cdot 63$ & $6 \cdot 58$ & $2 \cdot 708$ & $38 \cdot 55$ & $57 \cdot 12$ & $0 \cdot 218$ & $1 \cdot 482$ & 169 & $4 \cdot 496$ & $4 \cdot 55$ & 518 \\
\hline $0 \cdot 402$ & 0.598 & - & - & $44 \cdot 14$ & $6 \cdot 27$ & $2 \cdot 748$ & $30 \cdot 75$ & 54.94 & $0 \cdot 217$ & 1.787 & 173 & $4 \cdot 799$ & 4.60 & 519 \\
\hline 0.45 & $0 \cdot 50$ & 0.05 & - & $40 \cdot 02$ & $6 \cdot 92$ & 2.774 & $38 \cdot 61$ & $60 \cdot 04$ & $0 \cdot 217$ & $1 \cdot 555$ & 168 & 4.489 & $4 \cdot 60$ & 513 \\
\hline $0 \cdot 40$ & 0.55 & 0.05 & - & $40 \cdot 60$ & $6 \cdot 90$ & $2 \cdot 813$ & 37.97 & $60 \cdot 33$ & $0 \cdot 216$ & $1 \cdot 589$ & 172 & 4.537 & 4.65 & 511 \\
\hline $0 \cdot 35$ & $0 \cdot 60$ & $0 \cdot 05$ & - & 41.66 & $6 \cdot 79$ & $2 \cdot 848$ & $37 \cdot 33$ & 59.91 & $0 \cdot 216$ & 1.605 & 176 & 4.585 & $4 \cdot 70$ & 506 \\
\hline $0 \cdot 30$ & $0 \cdot 65$ & 0.05 & - & $42 \cdot 62$ & $6 \cdot 71$ & $2 \cdot 882$ & $36 \cdot 81$ & 59.67 & $0 \cdot 215$ & $1 \cdot 621$ & 180 & $4 \cdot 628$ & 4.75 & 504 \\
\hline $0 \cdot 45$ & $0 \cdot 50$ & - & $0 \cdot 05$ & $39 \cdot 79$ & $6 \cdot 96$ & 2.733 & $30 \cdot 9$ & $60 \cdot 54$ & $0 \cdot 218$ & 1.959 & 170 & 4.768 & 4.60 & 521 \\
\hline $0 \cdot 40$ & $0 \cdot 50$ & - & $0 \cdot 10$ & $40 \cdot 38$ & $7 \cdot 01$ & $2 \cdot 800$ & 31.9 & 61.54 & $0 \cdot 216$ & 1.929 & 174 & $4 \cdot 762$ & $4 \cdot 70$ & 523 \\
\hline $0 \cdot 35$ & $0 \cdot 50$ & - & $0 \cdot 15$ & $41 \cdot 46$ & 6.97 & $2 \cdot 867$ & $33 \cdot 2$ & $61 \cdot 75$ & $0 \cdot 215$ & $1 \cdot 860$ & 179 & 4.743 & $4 \cdot 80$ & 527 \\
\hline $0 \cdot 30$ & $0 \cdot 50$ & - & $0 \cdot 20$ & $42 \cdot 05$ & $7 \cdot 02$ & 2.933 & $33 \cdot 7$ & 62.69 & $0 \cdot 214$ & $1 \cdot 860$ & 183 & $4 \cdot 754$ & 4.90 & 528 \\
\hline $0 \cdot 25$ & $0 \cdot 50$ & - & $0 \cdot 25$ & $43 \cdot 20$ & $6 \cdot 97$ & $3 \cdot 000$ & 34.9 & 62.78 & $0 \cdot 213$ & 1.799 & 187 & $4 \cdot 737$ & $5 \cdot 00$ & 529 \\
\hline
\end{tabular}

Compositions and values of $T_{\mathrm{g}}$ of series $\mathrm{V}_{2} \mathrm{O}_{5}-\mathrm{PbO}$ were according to Paul et al (1999); $\mathrm{V}_{2} \mathrm{O}_{5}-\mathrm{PbO}-\mathrm{Li}_{2} \mathrm{O}$ were according to $\mathrm{Sa}-$ ddeek et al (2009) and $\mathrm{V}_{2} \mathrm{O}_{5}-\mathrm{PbO}-\mathrm{MoO}_{3}$ were according to Saddeek (2009).

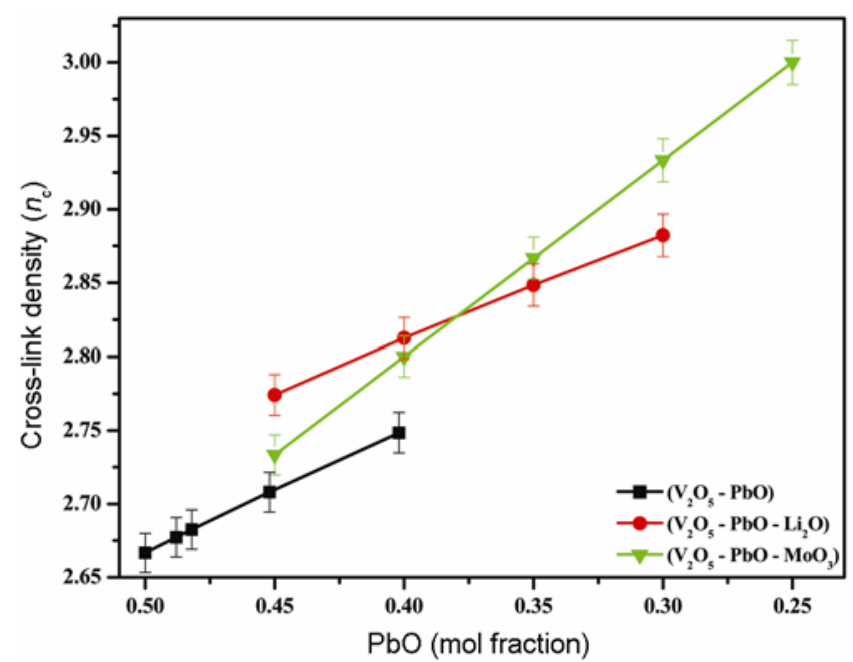

Figure 1. Compositional dependence of cross-link density on $\mathrm{PbO}$ content.

an increase in the molar volume, and the cross-link density along with decrease in the number of bonds per unit volume $\left(n_{\mathrm{b}}\right)$ as shown in figures 1-2 and as listed in table 2 . The decrease in the number of bonds per unit volume is attributed to the increase in molar volume, i.e. a decrease in the compactness of the glass network structure confirming the creation of bridging oxygens BOs (Saddeek et al 2009a, b). The increase in the molar volume is attributed to the replacement of $\mathrm{V}_{2} \mathrm{O}_{5}$ has packing density $35.4 \times 10^{-6} \mathrm{~m}^{3} \mathrm{~mol}^{-1}$ by $\mathrm{PbO}$ has packing density $9 \times 10^{-6}$ $\mathrm{m}^{3} \mathrm{~mol}^{-1}$ (Inaba et al 2003). Moreover, the increase in cross-link density is attributed to the decrease in number of cations in the glass network structure and $K_{\mathrm{bc}}$ as shown in figure 3. Thus, the structure will be more linked and the network of these glasses becomes more compact as the electronegativity and cation field strength of $\mathrm{PbO}$ are higher than that of $\mathrm{V}_{2} \mathrm{O}_{5}$. The average atomic ring diameter as shown in figure 4 increases as a direct result which is attributed to the increase in both molar volume (i.e. interatomic spacing) and BOs. The suggestion by Bridge et al (1983) that the ratio $K_{\mathrm{bc}} / K_{\mathrm{e}}$ (figure 5) is related to the average size of the rings may be accepted in fully polymerized glasses so; the relation between $K_{\mathrm{bc}} / K_{\mathrm{e}}$ and the average ring size of this type of glasses is straightforward. As reported earlier, as the value of the ratio $K_{\mathrm{bc}} / K_{\mathrm{e}}$ exceeds one, the connections between the structural units will be weaker and the structure becomes less stable. In addition, the decrease in the values of Poisson's ratio as shown in table 2 is mainly due to the increase in cross-link density while $K_{\mathrm{bc}}$ is found to increase and stretching force constant is found to decrease confirming that $\mathrm{PbO}$ has a pronounced bending effect on the behaviour of bond force constant.

3.1b $\mathrm{V}_{2} \mathrm{O}_{5}-\mathrm{Li}_{2} \mathrm{O}-\mathrm{PbO}$ series: According to table 2, the cross-link density increases and the $K_{\mathrm{bc}}$ decreases while the number of network bonds per unit volume decreases and the ring diameter increase as $\mathrm{PbO}$ content decreases. Also, the molar volume increases, oxygen molar volume decreased and the packing density (Saddeek et al 2009a, b) increases of these glasses with the decrease in $\mathrm{PbO}$ content. The increase in the average cross-link density is attributed to the replacement of $\mathrm{PbO}$ with $\mathrm{V}_{2} \mathrm{O}_{5}$ with higher coordination numbers which means the 
increase in dimensionality of the glass network structure. On the other hand, the decrease in the number of network bonds per unit volume (figure 2) from $6.92 \times 10^{28}$ to $6.71 \times 10^{28} \mathrm{~m}^{3}$ is attributed to the increase in molar volume and the decrease in oxygen molar volume which means the increase of BOs (Saddeek et al 2009a, b) with the decrease in $\mathrm{PbO}$ content. The computed values of these parameters are in a good agreement with the values given previously (Saddeek et al 2009a, b). The decrease in $\mathrm{PbO}$ content in the glass network results in the increased concentration of $\mathrm{VO}_{5}$ and $\mathrm{VO}_{6}$ structural units, as their coordination numbers are higher than $\mathrm{PbO}$ and hence lead to the increase in cross-link density. The decrease in $K_{\mathrm{bc}}$ with the decrease in $\mathrm{PbO}$ content is attributed to the replacement of $\mathrm{PbO}$ with higher electronegativity and

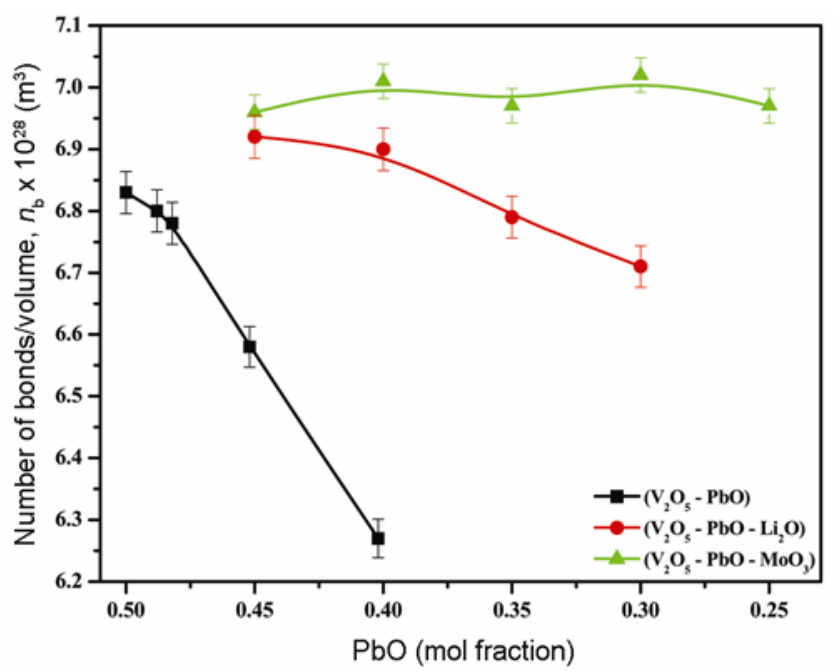

Figure 2. Compositional dependence of number of bonds per unit volume on $\mathrm{PbO}$ content.

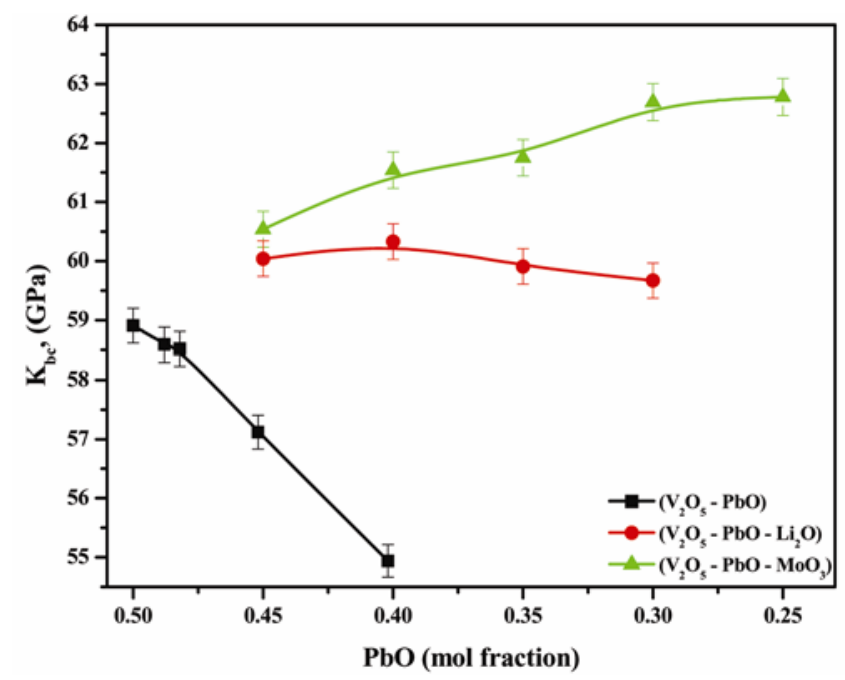

Figure 3. Compositional dependence of computed bulk modulus on $\mathrm{PbO}$ content. higher cation field strength by $\mathrm{V}_{2} \mathrm{O}_{5}$ with lower electronegativity and cation field strength. Therefore, the increase in the values of the ratio $K_{\mathrm{bc}} / K_{\mathrm{e}}$ and average ring diameter confirm the decreased rigidity of these glasses. Moreover, the decrease in the values Poisson's ratio confirm the change in the type of bonds from covalence to ionic, since the replacement of $\mathrm{PbO}$ (with higher cation field strength) by $\mathrm{V}_{2} \mathrm{O}_{5}$ would lead to the increase in the ionic cross-links and the increase in the average bond stretching force constant as seen in table 2 confirming the bending effect of $\mathrm{PbO}$. Therefore, the decrease in the elastic moduli of these glasses along with the increase in ionic cross-links indicating some change in the type of bonding (Rajendran et al 2003).

3.1c $\mathrm{V}_{2} \mathrm{O}_{5}-\mathrm{PbO}-\mathrm{MoO}_{3}$ series: Incorporation of $\mathrm{MoO}_{3}$ at the expense of $\mathrm{PbO}$ results in a markedly increase in

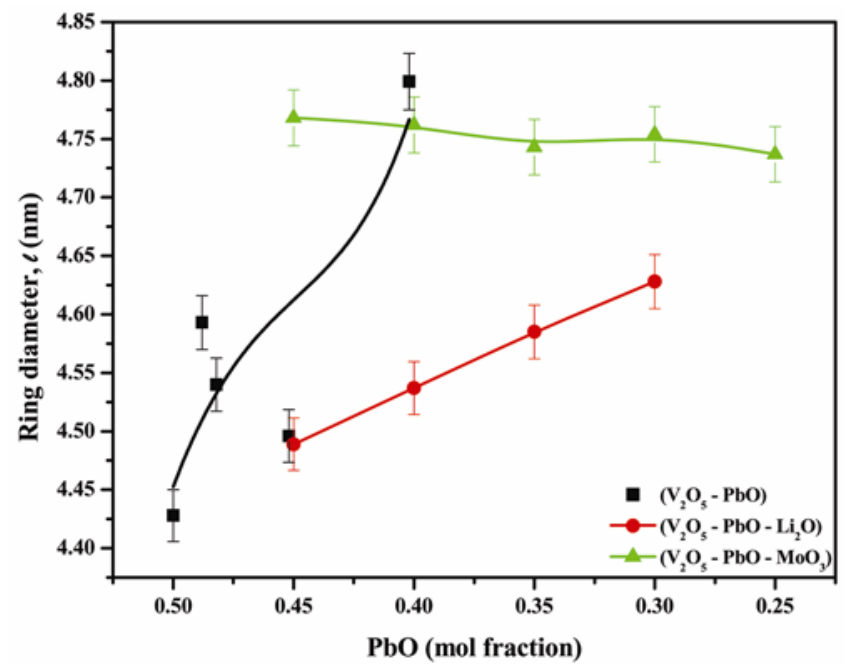

Figure 4. Compositional dependence of ring diameter on $\mathrm{PbO}$ content.

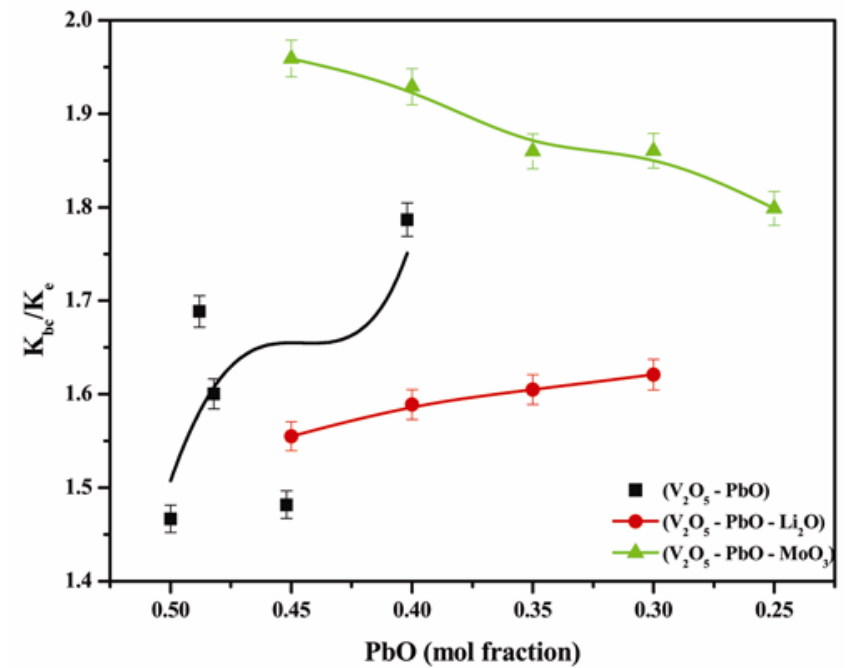

Figure 5. Compositional dependence of ratio $K_{\mathrm{bc}} / K_{\mathrm{e}}$ on $\mathrm{PbO}$ content. 
the molar volume and packing density (Saddeek et al 2009a, b). This incorporation will increase the average cross-link density and causes constancy in the total number of cations per unit glass formula unit (Bridge et al 1983; Bridge and Higazy 1986) and the number of network bonds per unit volume. In this type of glass, more polymerization will be created as the $\mathrm{PbO}$ content decreases, and as a result both the average ring diameter and $K_{\mathrm{bc}} / K_{\mathrm{e}}$ will decrease and the relation between them is straightforward. The behaviour of the last parameters with the decrease in $\mathrm{PbO}$ content is attributed to the role of the structural units $\mathrm{MoO}_{4}$ and $\mathrm{MoO}_{6}$ (Saddeek et al $2009 \mathrm{a}, \mathrm{b})$ confirming the increased rigidity of the glass network structure due to the replacement of $\mathrm{PbO}$ with lower bond strength by $\mathrm{MoO}_{3}$ with higher bond strength (Lide 2004). This behaviour was noticed (Gaafar et al $2009)$ in the experimental analysis of $\mathrm{Bi}_{2} \mathrm{O}_{3}-\mathrm{Er}_{2} \mathrm{O}_{3}-\mathrm{PbO}$ content glasses and was attributed to the role of $\mathrm{PbO}$. Moreover, the decrease in the values Poisson's ratio confirm the increased rigidity and strength of cross-link density of these glasses through the change in the type of bonds which would lead to the increase in the cross-link density (i.e. increase in rigidity) and the increase in the average bond stretching force constant $F$ as seen in table 2 .

It is inferred that as $\mathrm{PbO}$ content decreases in the studied vanadate based glasses, it will increase molar volume, average cross-link density and force constant and decrease the number of bonds per unit volume, while $K_{\mathrm{bc}}$ is very sensitive to the rate of increase of the molar volume. Accordingly, the relation between the average ring diameter and $K_{\mathrm{bc}} / K_{\mathrm{e}}$ depends on the polymerization or depolymerization of the vanadate network.

\subsection{Correlation between thermal properties and elastic moduli}

Recently, it was reported that the glass transition temperature $T_{\mathrm{g}}$ of glass-forming substances is a measure of structural packing of the network and is considered to be the temperature at which flow of the structure can be observed over long periods of time and the viscosity is just low enough (ca $10^{13}$ poise) to be measured accurately (Saddeek 2009). The glass transition temperature $T_{\mathrm{g}}$ can be related to some structural factors such as the average cross-link density and stretching force constant of each glass system. It was found that, $T_{\mathrm{g}}$ is an increasing function of both of $\bar{n}_{\mathrm{c}}$ and $f$ (El Mallawany et al 2002) with the decrease of $\mathrm{PbO}$ content as:

$$
T_{\mathrm{g}}=f\left(\bar{n}_{\mathrm{c}}, f\right) \text {. }
$$

In $\mathrm{PbO}-\mathrm{V}_{2} \mathrm{O}_{5}$ and $\mathrm{Li}_{2} \mathrm{O}-\mathrm{PbO}-\mathrm{V}_{2} \mathrm{O}_{5}$ glasses, as the $\mathrm{PbO}$ content decreases, non-bridging oxygens in the vanadate network will be created, so the structure will be loosed which requires a smaller internal energy barrier for chain mobility, which is needed for the glass transition. Thus, $T_{\mathrm{g}}, K_{\mathrm{bc}}$ and number of bonds per unit volume decrease while the ratio $K_{\mathrm{bc}} / K_{\mathrm{e}}$ and the ring diameter increase which is a direct result of the increase of the molar volume. The decrease in $K_{\mathrm{bc}}$ may be related to changes in the coordination number $Z$ of the constituent structural units of the glasses via the linear relationships: $\ln T_{\mathrm{g}}=$ $2.59 Z+0.03$ and $\ln T_{\mathrm{g}}=2.97 \mathrm{Z}-0.06$ for $\mathrm{PbO}-\mathrm{V}_{2} \mathrm{O}_{5}$ and $\mathrm{Li}_{2} \mathrm{O}-\mathrm{PbO}-\mathrm{V}_{2} \mathrm{O}_{5}$ glasses, respectively as shown in figure 6 . Thus, the molar volume and number of bonds per unit volume have greater effects on $T_{\mathrm{g}}$ and the activation energy for glass transition (Saddeek 2009) than the bond strength (Saddeek et al 2009a, b).

In the while, for $\mathrm{MoO}_{3}-\mathrm{PbO}-\mathrm{V}_{2} \mathrm{O}_{5}$ glasses, as the $\mathrm{PbO}$ content decreases, more bridging oxygens in the vanadate network will be created, i.e. the structure will be strengthened which is attributed to the former role of $\mathrm{MoO}_{3}$ and will require a larger internal energy barrier for chain mobility, which is needed for the glass transition causing an increase in the glass-transition temperature. Also, $K_{\mathrm{bc}}$, the stretching force constant and the average cross link density will increase while the ratio $K_{\mathrm{bc}} / K_{\mathrm{e}}$ and the ring diameter decrease which is a direct result of the increase of the bond strength. Therefore, the bond strength has greater effects on $T_{\mathrm{g}}$ and the activation energy for glass transition (Saddeek 2009) than the molar volume (Saddeek et al 2007). This increase may be related to changes in the coordination number $Z$ of the constituent structural units of the glasses via the linear relationship: $\ln T_{\mathrm{g}}=$ $2 \cdot 64 Z+0.02$ as shown in figure 6 .

The fascinating properties and wide range applications of $\mathrm{V}_{2} \mathrm{O}_{5}$ is especially interesting in thin film form because of the possibility of integration into micro-electronic circuitry and its application in optoelectronic devices. The properties of the $\mathrm{V}_{2} \mathrm{O}_{5}$ films are mainly dependent on the deposition technique and the deposition conditions

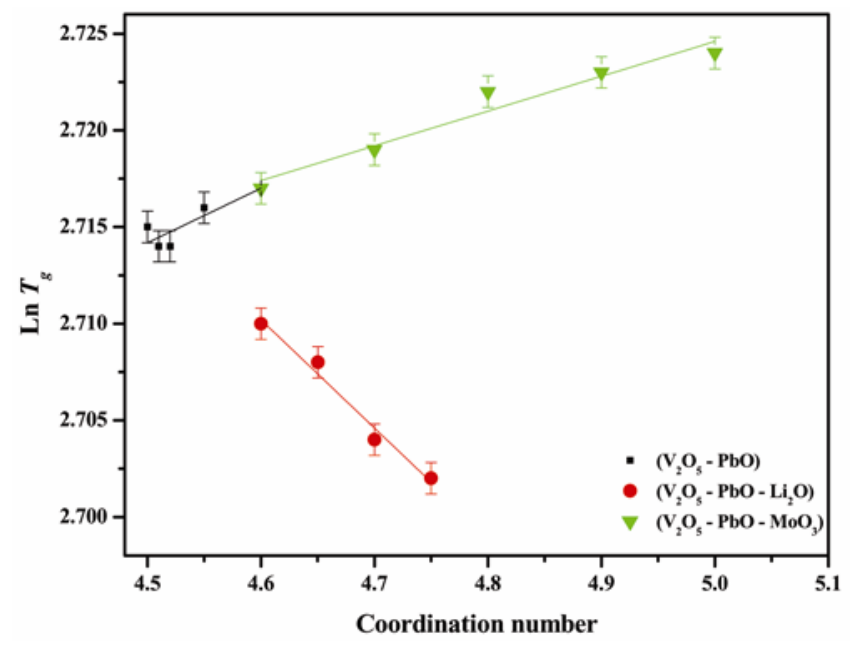

Figure 6. Dependence of glass transition temperature on coordination number. 
such as vacuum, deposition temperature, etc. The deposition temperature in its turn depends on the melting temperature $\left(T_{\mathrm{m}}\right)$ of the material and consequently on its $T_{\mathrm{g}}$. Another decisive parameter in the fabrication of the solar cell is the thermal stability which depends on the difference between $T_{\mathrm{g}}$ and $T_{\mathrm{m}}$ (Aly et al 2010, 2013). Thermal stable solar cell undergoes long times to the exposure of sun. On the basis of these arguments, Kumar et al (2008) coated amorphous glass substrates by homogeneous, uniform and amorphous $\mathrm{V}_{2} \mathrm{O}_{5}$ thin films by using vacuum evaporation technique at deposition temperature of $573 \mathrm{~K}$. Deposition temperature is found to have a great impact on the optical and structural properties of these films. Therefore, addition of $\mathrm{PbO}$ and $\mathrm{MoO}_{3}$ to $\mathrm{V}_{2} \mathrm{O}_{5}$ based glasses will reinforce such coating or thin film.

Thus, it is inferred from the former analysis that, the glass has the composition $0 \cdot 25 \mathrm{MoO}_{3}-0 \cdot 25 \mathrm{PbO}-0 \cdot 5 \mathrm{~V}_{2} \mathrm{O}_{5}$ is more rigid one and its glass transition temperature is suitable for thermal evaporation for the use as a thin film and coating for the fabrication of inexpensive solar cells.

\section{Conclusions}

In $\mathrm{PbO}-\mathrm{V}_{2} \mathrm{O}_{5}$ and $\mathrm{Li}_{2} \mathrm{O}-\mathrm{PbO}-\mathrm{V}_{2} \mathrm{O}_{5}$ glasses, as the $\mathrm{PbO}$ content decreases, non-bridging oxygens in the vanadate network will be created due to the increase in the molar volume, so the structure will be loosed and $K_{\mathrm{bc}}$ decreases. This decrease may be related to the changes in the coordination number $Z$ of the constituent structural units of the glasses which is attributed to the effects of the molar volume and number of bonds per unit volume on $T_{\mathrm{g}}$ and the activation energy for glass transition than the bond strength.

While in $\mathrm{MoO}_{3}-\mathrm{PbO}-\mathrm{V}_{2} \mathrm{O}_{5}$ glasses, as the $\mathrm{PbO}$ content decreases, more bridging oxygens in the vanadate network will be created, i.e. the structure will be strengthened which is attributed to the former role of $\mathrm{MoO}_{3}$. Thus, $K_{\mathrm{bc}}$, the stretching force constant and the average crosslink density will increase while the ratio $K_{\mathrm{bc}} / K_{\mathrm{e}}$ and the ring diameter decrease which is a direct result of the increase of the bond strength. Therefore, the bond strength has greater effects on $T_{\mathrm{g}}$ and the activation energy for glass transition than the molar volume.

The glass has the composition $0 \cdot 25 \mathrm{MoO}_{3}-0 \cdot 25 \mathrm{PbO}-$ $0.5 \mathrm{~V}_{2} \mathrm{O}_{5}$ is more rigid one and its glass transition temperature is suitable for thermal evaporation for the use as a thin film and coating.

\section{Acknowledgement}

This work was financially supported by the Engineering and Applied Sciences research centre-Majmaa university - Kingdom of Saudi Arabia under Contract 12.

\section{References}

Agostinelli E, Filaci, Fiorani D, Montenero A and Bettinelli M 1986 J. Non-Cryst. Solids 84329

Aly K, Dahshan A and Saddeek Y 2010 J. Therm. Anal. Calor. 100543

Aly K, Hassaan M and Saddeek Y 2013 Phase Transitions doi: 10.1080/01411594, 703668

Bahgat A, El-Samanoudy M and Sabry A 1999 J. Phys. Chem. Solids 601921

Baiocchi E, Bettinelli M, Motenero A and Disipio A $1982 J$. Solid State Chem. $\mathbf{4 3} 63$

Bridge B, Patel N and Waters D 1983 Phys. Stat. Solidi A77 655

Bridge B and Higazy A 1986 Phys. Chem. Glasses 271

Calestani G, Montenero A, Pigoli F and Bettinelli M $1985 \mathrm{~J}$. Solid State Chem. $\mathbf{5 9} 357$

Dimitriev Y and Mihailova V 1990 J. Mater. Sci. Lett. 91251

Dimitriev Y, Jordanova Y and Gateff E 1981 J. Non-Cryst. Solids $\mathbf{4 5} 297$

Dimitriev Y, Dimitrov V, Arnandov M and Topalov D 1983a J. Non-Cryst. Solids 57147

Dimitriev Y, Ivanova I and Gatev E 1983b J. Non-Cryst. Solids 45293

Dimitrov V 1995 J. Non-Cryst. Solids 192183

Dimitrov V and Dimitriev Y 1990 J. Non-Cryst. Solids 122 133

Dumbaugh W and Lapp J 1992 J. Am. Ceram. Soc. 752315

El Mallawany R 2002 Tellurite glasses physical properties and data (New York: CRC Press)

EL-Mallawany R, Hager I and Poulain M 2002 J. Mater. Sci. 37 3291

Gaafar M, Marzouk S and Mady H 2009 Phil. Mag. 892213

Ghosh A 1988 J. Appl. Phys. 642652

Hand R, Short R, Morgan S, Hyatt N, Mbus G and Lee W 2005 Glass Technol. 46121

Hayakawa S, Yoko T and Sakka S 1995 J. Non-Cryst. Solids 18373

Inaba S, Oda S and Morinaga K 2003 J. Non-Cryst. Solids 325 258

Iordanova R, Dimitrov V, Dimitriev Y and Klissurski D 1994 J. Non-Cryst. Solids 18058

Josso G and Calvarin G 1986 J. Solid State Chem. 64225

Kawamoto Y, Fukuzuka M, Ohta Y and Imai M 1979 Phys. Chem. Glasses 2054

Kawamoto Y, Tanida J, Hamada H and Kiriyama H $1980 \mathrm{~J}$. Non-Cryst. Solids 38301

Kumar A, Singh P, Kulkarni N and Kaur D 2008 Thin Solid Films $\mathbf{5 1 6} 912$

Lide D 2004 CRC handbook of chemistry and physics (Boca Raton, Fl: CRC Press) 84th edn

Livage J, Jolivet J and Trone E 1990 J. Non-Cryst. Solids 121 35

Mandal S and Ghosh A 1993 Phys. Rev. B48 9388

Mandal S and Ghosh A 1999 Phil. Mag. B79 1175

Momo F, Sotgin A, Baicchi E, Bettinelli M and Montenero A 1982 J. Mater. Sci. 173221

Montani R, Levy M and Souquet J 1992 J. Non-Cryst. Solids 149249

Mouhsine N, Bih L, Allali N, Nadiri A, Yacoubi A, Haddad M and Danot M 2003 Solid State Sci. 5669 
Music S, Gotic M, Popovic S, Furic K and Mohacek V 1994 J. Mater. Sci. 291227

Paul A, Maiti A and Basu C 1999 J. Appl. Phys. 863598

Pauling L 1940 Nature of chemical bond and structure of molecules and crystals (New York, Ithaca: Cornell University Press) 2nd edn

Pisarska J, Lisiecki R, Ryba-Romanowski W, Dominiak-Dzik G and Pisarski W 2008 J. Alloys Compd. 451226

Qiu H, Kudo M and Sakata H 1997 Mater. Chem. Phys. 51 233

Rajendran V, Palanivelu N, Chaudhuri B and Goswami K 2003 J. Non-Cryst. Solids 320195

Ramesh K and Sastry D 2006 J. Non-Cryst. Solids 352 5421
Rao K 2002 Structural chemistry of glasses (North-Holland: Elsevier)

Saddeek Y, Shaaban E, Aly K and Sayed I 2009a J. Alloys Compd. $\mathbf{4 7 8} 447$

Saddeek Y, Shaaban E, Aly K and Sayed I 2009b Physica B 4042412

Saddeek Y 2009 Philos. Mag. 892305

Saddeek Y 2009 Philos. Mag. 8941

Saddeek Y, Afifi H and Abd El-Aal N 2007 Physica B398 1

Sidkey M, El-Mallawany R, Abousehly A and Saddeek Y 2002 Mater. Chem. Phys. $\mathbf{7 4} 222$

Wells A 1975 Structural inorganic chemistry (Oxford: Clarendon Press) 4th edn 